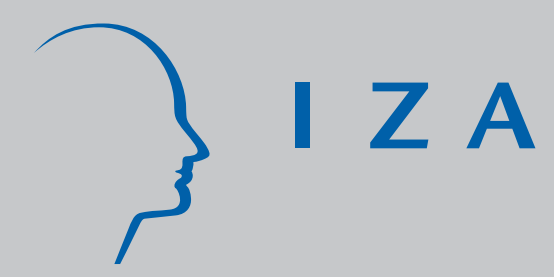

IZA DP No. 1389

Information and Racial Exclusion

Shelly Lundberg

Richard Startz

November 2004 


\title{
Information and Racial Exclusion
}

\author{
Shelly Lundberg \\ University of Washington \\ and IZA Bonn
}

Richard Startz

University of Washington

\section{Discussion Paper No. 1389 \\ November 2004}

\author{
IZA \\ P.O. Box 7240 \\ 53072 Bonn \\ Germany \\ Phone: +49-228-3894-0 \\ Fax: +49-228-3894-180 \\ Email: iza@iza.org
}

Any opinions expressed here are those of the author(s) and not those of the institute. Research disseminated by IZA may include views on policy, but the institute itself takes no institutional policy positions.

The Institute for the Study of Labor (IZA) in Bonn is a local and virtual international research center and a place of communication between science, politics and business. IZA is an independent nonprofit company supported by Deutsche Post World Net. The center is associated with the University of Bonn and offers a stimulating research environment through its research networks, research support, and visitors and doctoral programs. IZA engages in (i) original and internationally competitive research in all fields of labor economics, (ii) development of policy concepts, and (iii) dissemination of research results and concepts to the interested public.

IZA Discussion Papers often represent preliminary work and are circulated to encourage discussion. Citation of such a paper should account for its provisional character. A revised version may be available directly from the author. 


\section{ABSTRACT}

\section{Information and Racial Exclusion*}

This paper presents several economic models that explore the relationships between imperfect information, racial income disparities, and segregation. The use of race as a signal arises here, as in models of statistical discrimination, from imperfect information about the return to transactions with particular agents. In a search framework, signaling supports not simply a discriminatory equilibrium, but a pattern of racially segregated transactions, which in turn perpetuates the informational asymmetries. Minority groups necessarily suffer disproportionately from segregation, since the degree to which transactions opportunities are curtailed depends upon group size, as well as the informational "distance" between racial groups. However, in some variants of the model, minority agents will self-segregate since they face an adverse selection of majority agents who are willing to trade with them. We also show that, if agents are able to learn from transactions, racial signaling can emerge with only minimal assumptions about the ex ante importance of race.

JEL Classification: J7, D83

Keywords: race, segregation, discrimination, imperfect information, search

Corresponding author:

Richard Startz

Department of Economics

University of Washington

Seattle, WA 98195-3330

USA

Email: startz@u.washington.edu

\footnotetext{
* Extensive comments from Fahad Khalil and seminar participants at Simon Fraser University are greatly appreciated. We are grateful to the John D. and Catherine T. MacArthur Foundation for financial support.
} 
In any review of the current state of race relations in America, two important economic facts stand out: the continued disparity in income between black and white Americans, and the pervasive racial segregation of neighborhoods, schools, and social networks. After declining in the 1980s, the relative income of African-American households rose in the late 1990s to about $65 \%$ of white household income. ${ }^{1}$ However, the earnings of black men working full-time have remained at about $70 \%$ of the full-time earnings of white men for the past 30 years. Residential segregation in urban America remains extremely high, though levels of segregation decreased slowly and unevenly throughout the past three decades. ${ }^{2}$ Black-white segregation in schools, however, appears to have increased. ${ }^{3}$

In this paper we explore the relationship between imperfect information, racial disparities, and segregation. We take as a primitive assumption that when an agent thinks about the value of engaging in trade with another person, the agent uses race in forming her conditional probability distribution over outcomes. The unconditional distribution of quality is assumed to be the same for each race, but we assume that agents are better able to separate signal from noise in inferring the value of trade for one group than for the other. Consider a search theoretic model in which the searcher can identify individual opportunities to trade with members of one group as being of "high" or "low" value, while the opportunities to trade with members of the other group "all look alike." An observably high value trade from the first group will always be taken. But depending on the costs of search, etc., agents may rationally choose to refuse all trades with

${ }^{1}$ U.S. Census Bureau [2001].

2 Farley and Frey [1994] document decreases in segregation in most metropolitan areas during the 1990s, and Glaeser and Vigdor [2001] find that the trend continues in the 2000 Census. They find that segregation declined most sharply in fast-growing areas with small black populations, and that the largest metropolitan areas remain highly segregated.

${ }^{3}$ Reardon, Yun, and Eitle [2000] find that segregation between non-Hispanic white students and all other students increased between 1989 and 1995, while segregation between minority groups declined. 
members of the second group because the expected return of waiting for the opportunity to trade with a high value member of the first group is higher. In this way, imperfect information can lead to transactions that are segregated by group.

We begin by setting up a one-sided search model without group distinctions, and then extend this to allow trading partners to be members of a majority (white) group or a minority (black) group. Searching agents are more adept at reading signals emitted by members of the majority, and are therefore better able to identify whether a potential trading partner is of high or low value when the trading partner is white. The general results from the one-sided model are intuitive--members of the minority group are more likely to excluded from trade when: (1) the minority is relatively small, as the costs of waiting for an opportunity to trade with a majority partner is less; (2) the minority is "informationally distant" from the searcher, that is when the "they all look alike" factor is important; and (3) when the potential return from waiting for a high value trade is large relative to the cost of search.

Next we turn to a model of two-sided search in which both parties must agree to a trade. The information structure is an asymmetric one in which black agents are better informed-they are able to read the signals of both black and white potential partners, while white agents are only able to read the signals of white partners. We make this assumption because we think it represents a useful, if highly stylized, picture of race relations in the United States. In general, there are multiple Nash equilibria in this two-sided search game. We demonstrate computationally that high-value black agents may choose to voluntarily self-segregate, and examine the conditions under which this outcome is more likely. The intuition is that high-value black agents face an adverse selection problem: they can infer that a white potential partner who 
is willing to trade with them is low-value. Though black agents in this model possess better information than white agents, their relative wellbeing depends upon how their own signals are valued in equilibrium.

To this point we have assumed that the information structure is given. In our third model we return to one-sided search, but allow information to be acquired through previous trades with a member of a given group - call it "learning by trading." We then consider search which is strategic in the sense that forward-looking agents realize that part of the return to a trade this period is that it makes trades with members of the same group more profitable in future periods. The bigger the group learned about, the greater the value of the information acquired, and we show that minority agents may be completely excluded from trade.

In general, this paper shows that racial segregation of transactions can arise in a variety of circumstances, and for several different reasons. In a model with exogenous information, agents may choose to exclude all members of a particular group from trades. In a racial context, the interaction between cultural dissimilarity and minority status generates segregation and disadvantage for black agents. These effects are magnified in a model with learning, since the value of trade will be increasing in the size of the partner's group. In a model of two-sided search, in which agents on both sides vary by race and ability, an additional motive for strategic segregation is added. Mutual racial segregation of high-ability agents can occur, and this equilibrium is disadvantageous to minority agents. Although minority agents have a greater informational endowment than majority agents and have an identical distribution of ability, minority welfare is lower in the search equilibrium. The model thus generates income differentials based not on ability differences nor on biased expectations, but on informational externalities that arise from minority status and the obtuseness of majority agents. 


\section{Background and Literature}

The relationship between residential segregation, social isolation, and economic inequality has been explored by the sociologist Douglas Massey, who argues that spatial concentration of groups by race or class contributes to the persistence of poverty and growing inequality. ${ }^{4}$ Economists, however, have in general analyzed the nature and causes of racial income inequality outside the context of racial segregation. Economic models of discrimination focus on formal (and impersonal) labor market transactions, in which differential treatment of agents with the same level of human capital presents an arbitrage opportunity to competitors. ${ }^{5}$ Though the importance of group affiliation is recognized in the literature on networks and neighborhoods, the role of segregation as either a cause or effect of income disparities has received little attention. Recent exceptions have included research emerging from the Multi-City Study of Urban Inequality, which examine the relationship between residential segregation, job location, employer and worker attitudes, and labor market disadvantage. ${ }^{6}$

Kenneth Arrow has argued that social interactions should play a larger role in economists' analyses of racial discrimination since personal transactions, unmediated by the market, can affect beliefs and preferences and therefore resource allocations. ${ }^{7}$ The separation of black and white agents implied by pervasive racial segregation in housing, schools, and social networks affects the pattern of nonmarket transactions, and is likely to be economically

\footnotetext{
${ }^{4}$ For example, see Massey [1996] and Massey and Denton [1993].

${ }^{5}$ For a recent survey of economic theories of race and gender disparities in labor market outcomes, see Altonji and Blank [1999].

${ }^{6}$ Holzer [1996], O’Connor, Tilly, and Bobo [2000].

7 See Arrow [1998]. For a taste of the exploding literature on social interactions, see Durlauf and Young [2001].
} 
significant through linkages between location, the density of transactions between groups of agents, and the flow of information. ${ }^{8}$

The next step, from a racially-distinct information structure to group income disparities, has been well-trodden by economists. Models of statistical discrimination, though they involve formal market mechanisms, assume that information has a racial dimension and takes that information structure as given. Theories of group disparities that are based on imperfect information about productivity include those of Arrow [1973], Phelps [1972], Aigner and Cain [1977], Lundberg and Startz [1983], and Coate and Loury [1993]. Segregation per se is not a feature of these models, either as a source of imperfect information, or as an outcome of discrimination. However, a pattern of transactions with minimal contact between black and white agents can be expected to reinforce (and be reinforced by) the racial information asymmetries that drive statistical discrimination.

In this paper we generate both racial income disparities and segregation by incorporating the information structure of a statistical discrimination model into a search framework. ${ }^{9}$ In a search model, because transactions are discrete and rival, imperfect signaling will support not just a discriminatory equilibrium, but a pattern of racially segregated transactions which can in turn perpetuate the informational asymmetries. Each agent participates in at most one transaction per period, and searches sequentially for an acceptable partner. The opportunity cost of a particular transaction will therefore be the foregone expected value of meeting a better partner

\footnotetext{
${ }^{8}$ The importance of social, as well as market, transactions in generating patterns of racial inequality has also been emphasized by Loury [1998]. Social networks affect labor market opportunities, and neighborhood externalities may be important influences on preference, attitudes, and behavior.

${ }^{9}$ Mailath, Samuelson, and Shaked [2000] present a very different two-sided search model of discrimination in which "red" and "green" workers search for vacancies, and firms search for workers. They show that asymmetric equilibria exist in which more green than red workers acquire skills, and skilled green workers receive higher wages.
} 
with continued search. This discrete search framework is appropriate for many of the important transactions engaged in by individuals and families who choose jobs, neighborhoods and schools, friends and suppliers.

\section{Model 1: One-Sided Search with Exogenous Information}

We begin with a model of search for a trading partner in which information plays no strategic role, but in which informational asymmetries can generate racially segregated transactions. In this section, we show that agents may choose to discriminate (i.e. refuse to trade with members of one racial group) even though the groups are known to have the same quality distribution, ${ }^{10}$ that discrimination occurs when searchers are relatively uninformed about the quality of individual agents, and that discrimination is more likely to occur against members of a minority group.

In this simple model, homogeneous agents search for transactions partners. The potential partners are heterogeneous, and the value of a transaction to the searcher depends upon a fixed characteristic of the partner that we call "ability". The searcher meets with potential partners sampled randomly (with replacement) from a pool with a known ability distribution, and receives a signal that is an imperfect indicator of ability. ${ }^{11}$ On the basis of this signal, the searcher decides whether to engage in a transaction or to reject the potential partner and search further. Once a transaction takes place, search ends. Our tasks are, first, to determine the optimal strategy for a searcher faced with imperfect ability signals and, second, to describe the

\footnotetext{
${ }^{10}$ See also Cornell and Welch (1996) for a similar result with a somewhat more formal model of the information arrival process. Cornell and Welch also present a discussion of why culture may matter in the screening process.

${ }^{11}$ Signals are assumed immutable, so they correspond in the terminology of Spence (1973) to "indices."
} 
conditions under which, if there are two groups of potential partners, the searcher will treat them differently.

Search without Racial Identifiers:

A searcher faces a pool of potential partners with two ability levels: high $\left(a_{H}\right)$ and low $\left(a_{L}\right)$. A proportion $\alpha$ of potential partners are of high ability, while $(1-\alpha)$ are of low ability. Agents observe for each potential partner either a high signal $\left(s_{H}\right)$ or a low signal $\left(s_{L}\right)$ that reflects ability with error. The signal correctly reveals ability with probability $q$, where $q \geq \frac{1}{2}$. The probability of meeting a partner of ability type $a$ is $p(a)$, i.e. $\alpha$ or $1-\alpha$. The probability of observing a type $a$ conditional on a signal $s$ is $p(a \mid s)$, for example the conditional probability of meeting a high quality partner, given that a high signal is observed, is $p\left(a_{H} \mid s_{H}\right)=\alpha q /(\alpha q+(1-\alpha) \cdot(1-q))$. Conditional on a trade being executed, the payoffs $Q_{H}$ and $Q_{L}$ depend on the ability of the trading partner, and we assume that $Q_{H}>Q_{L}$.

The static problem of the agent is to calculate the expected gain from trade with a potential partner, conditional on the observed signal. The dynamic problem is to choose an optimal search strategy consisting of a set of trade/no trade decision rules that maximizes the expected return to searching for a partner. An optimal strategy defines a set of acceptable signals, $\varphi$, that maximizes the value function:

$$
V=-d+p(s \in \varphi) \cdot E[Q \mid s \in \varphi]+[1-p(s \in \varphi)] \cdot V
$$


where $d$ is the cost of search, $E[Q \mid s \in \varphi]$ is the expected payoff of the transaction, given that the potential partner's signal is acceptable to the searcher, and the last term is the expected gain to continued search. ${ }^{12}$

Faced with a potential partner, an agent will trade if and only if the expected value of the transaction is greater than the value of continued search given the optimal strategy. ${ }^{13}$ The expected value, $R$, of a transaction with an agent signaling $s$ is:

$$
R(s)=p\left(a_{L} \mid s\right) \cdot Q_{L}+p\left(a_{H} \mid s\right) \cdot Q_{H}
$$

while the unconditional payoff is: $R^{U}=(1-\alpha) \cdot Q_{L}+\alpha \cdot Q_{H}$.

If the signal is informative, $R\left(s_{H}\right) \geq R^{U} \geq R\left(s_{L}\right)$. The agent's optimal strategy is to choose a reservation signal $s^{*} \in\left\{s_{L}, s_{H}\right\}$ such that $R\left(s^{*}\right) \geq V^{*}$ and trade with partners where $s \geq s^{*}$. There are only two options: to be unselective and trade with any partner, or to be selective and decline to trade with those who signal low. It is straightforward to show that the optimal strategy depends upon the cost of searching, the payoff structure and the information structure. The more accurate is the signal and the greater is the differential in payoff between high-ability and low-ability partners, the more likely is the searcher to be selective. ${ }^{14}$

${ }^{12}$ Given the presence of search costs, $d$, nothing interesting would be gained by explicitly discounting future gains in equation (1); so we don't.

${ }^{13}$ This is the usual search theoretic result. In this context it can be shown directly by differentiating $V^{*}$ with respect to the element of $s$ corresponding to signal $j$.

${ }^{14}$ With completely informative signals $(q \rightarrow 1), R\left(s_{H}\right), R^{U}$, and $R\left(s_{L}\right)$ approach $Q_{H}>(1-\alpha) \cdot Q_{L}+\alpha \cdot Q_{H}>Q_{L}$, while with uninformative signals $(q \rightarrow 1 / 2)$ they all approach $(1-\alpha) \cdot Q_{L}+\alpha \cdot Q_{H}$. 


\section{$\underline{\text { Search with Two Racial Groups: }}$}

When potential partners possess observable characteristics other than signal value, agents may be able to draw more accurate inferences about the ability of some partners than about the ability of others (or to believe that they can do so). In particular, we expect agents to be able to 'read' more reliably the signals from agents belonging to groups with whom they have some cultural affinity, or more transactions experience. Group differences in the signal-to-noise ratio of information are standard devices in the statistical discrimination literature, and are assumed to arise when agents can more easily observe the signal from one group (especially the group to which they belong) or are more proficient in understanding the signal. For example, in Phelps [1972], Aigner and Cain [1977], and Lundberg and Startz [1983], the signal-to-noise ratio for black workers' productivity is lower than that of white workers, and this leads to a minority compensation schedule in which less weight is placed on individual indicators of productivity. In the absence of endogenous human capital investments, however, these models do not result in differential average treatment by race — average wages equal average productivity. In this section, we show that in a search model, the same type of differential information can lead to discrimination that takes the form of exclusion of an entire racial group and thus differences in average treatment.

We can allow information quality to vary by making $q$, the probability that a signal correctly reveals ability, a function of the informational "distance" between the searcher and the group of agents being sampled. For some group of potential partners, $i$, let

$q^{i}=(1-\omega) \cdot q^{\max }+\omega \cdot \frac{1}{2}$ where $1 \geq q^{\max } \geq \frac{1}{2}$ and $0 \leq \omega \leq 1$ is an index of the distance between the searcher and potential partners. The less the informational distance between agent and potential 
partner, the higher $q^{i}$, the better informed the agent, and greater the expected return from trade with a partner signaling high versus a partner signaling low. We call the searcher fully informed with respect to group $i$ if $\omega=0$ and $q^{i}=q^{\max }$. The searcher is uninformed if $\omega=1$ and $q^{i}=\frac{1}{2}$. Being uninformed with respect to a group of potential partners is equivalent to being unable to observe their signals.

An increase in informational distance between searcher and partner reduces the expected value of a transaction conditional on a high signal, and increases the expected value of a low signal. If $R$ is the expected value of a transaction by a fully informed agent $\left(q=q^{\max }\right)$ and $R^{\omega}$ is expected transaction value when $\omega>0$, then $R\left(s_{H}\right) \geq R^{\omega}\left(s_{H}\right) \geq R^{\omega}\left(s_{L}\right) \geq R\left(s_{L}\right)$. With two racially-defined groups of agents, we can represent the inter-group signaling difficulties of the statistical discrimination literature as informational distance.

We now assume that the searcher draws potential partners from a pool containing two groups, a majority race (white) and minority race (black) denoted $W$ and $B$, where a proportion $\mu(>0.5)$ of the population consists of white partners, while the remaining $(1-\mu)$ are black. Let the searcher be fully informed $(\omega=0)$ about one group, e.g. $W$, and not the other $(\omega>0), B$. The proportion of high-ability partners is known to be the same in both groups. This assumption is maintained throughout, and no results will depend upon racial differentials in the distribution of ability, nor upon biased beliefs about these distributions. The underlying payoff structure of transactions with black and white partners is assumed to be identical, so that differential treatment is based solely on differences in the information structure. 
Potential partners can now be distinguished on the basis of race and signal. There are four observable race/signal pairs, $\left\{W s_{L}, W s_{H}, B s_{L}, B s_{H}\right\}$, and a strategy consists of trade/no-trade rules for each pair. An agent chooses an optimal strategy from the set of $2^{4}$ possible permutations of decision rules. So a strategy $Z$ maps race/signal pairs into trade/no-trade choices, $Z:\{W, B\} \times\left\{s_{L}, s_{H}\right\} \rightarrow\{1,0\}$

A number of possible strategies can be ruled out: We assume that the return to search is positive, so that it is never optimal to refuse all potential partners. Since $R\left(s_{H}\right) \geq R^{\omega}\left(s_{H}\right) \geq R^{\omega}\left(s_{L}\right) \geq R\left(s_{L}\right)$ and agents trade when expected return exceeds $V^{*}$, the ranking of possible trades is $W s_{H} \succ B s_{H} \succ B s_{L} \succ W s_{L}$. The only four possible strategies $\varphi=\left\{\left(s_{W}^{*}, s_{B}^{*}\right)\right\}$ are $\left(s_{W}^{*}, s_{B}^{*}\right) \in\left\{\left(s_{L}, s_{L}\right),\left(s_{H}, s_{L}\right),\left(s_{H}, s_{H}\right),\left(s_{H}, \infty\right)\right\}$, where a reservation signal $s_{L}$ implies "accept all trades" and a reservation signal $\infty$ means "refuse all trades." The last strategy, $\left(s_{W}^{*}, s_{B}^{*}\right)=\left(s_{H}, \infty\right)$ is of interest because potential black partners are excluded from trade even if they signal high ability.

We can determine the optimal strategy by calculating and comparing the value functions for each possible strategy, $V\left(s_{W}^{*}, s_{B}^{*}\right)$.

Unselective:

$$
V\left(s_{L}, s_{L}\right)=-d+R^{U}
$$


Selective $W$, unselective $B$ :

$$
\begin{aligned}
V\left(s_{H}, s_{L}\right) & =-d+\mu \cdot p\left(s_{H}\right) \cdot R\left(s_{H}\right)+(1-\mu) \cdot R^{U}+\left(1-\mu \cdot p\left(s_{H}\right)-(1-\mu)\right) \cdot V\left(s_{H}, s_{L}\right) \\
& =\frac{-d+\mu \cdot p\left(s_{H}\right) \cdot R\left(s_{H}\right)+(1-\mu) \cdot R^{U}}{\left(\mu \cdot p\left(s_{H}\right)+(1-\mu)\right)}
\end{aligned}
$$

Selective $W$, selective $B$ :

$$
\begin{aligned}
V\left(s_{H}, s_{H}\right) & =-d+\mu \cdot p\left(s_{H}\right) \cdot R\left(s_{H}\right)+(1-\mu) \cdot p\left(s_{H}\right) \cdot R^{\omega}\left(s_{H}\right)+\left(1-p\left(s_{H}\right)\right) \cdot V\left(s_{H}, s_{H}\right) \\
& =\frac{-d}{p\left(s_{H}\right)}+\mu \cdot R\left(s_{H}\right)+(1-\mu) \cdot R^{\omega}\left(s_{H}\right)
\end{aligned}
$$

Selective $W$, exclude $B$ :

$$
\begin{aligned}
V\left(s_{H}, \infty\right) & =-d+\mu \cdot p\left(s_{H}\right) \cdot R\left(s_{H}\right)+\left(1-\mu \cdot p\left(s_{H}\right)\right) \cdot V\left(s_{H}, \infty\right) \\
& =\frac{-d}{\mu \cdot p\left(s_{H}\right)}+R\left(s_{H}\right)
\end{aligned}
$$

Before presenting some general results about racial exclusion, we use equations (3a)-(3d) to graphically illustrate some of the possible search strategy patterns that this model can generate. Figures 1 through 3 plot the value functions (3a)-(3d) for selected values of the parameters. In Figure 1, we vary $q^{\max }$, the quality of information and the advantage of trading with group $W$ versus group $B$. At low values of $q^{\max }$, the nonselective, take-all-comers, strategy produces the highest value of search. As the information value of the signal increases, however, the selective strategies gain in relative value. For mid-range values of $q^{\max }$, the searcher will be selective with respect white partners, but will continue to trade with all black potential partners, who appear to be relatively more homogeneous. For high values of $q^{\max }$, however, the optimal 
strategy is exclusive, and the searcher will refuse to trade with all partners except high-signaling whites. $^{15}$

In Figure 2, we vary the informational distance between groups, $\omega$. When this distance is small, it makes sense to treat whites and blacks alike; with the given parameters this means trading only with agents who signal high. In contrast, when distance between the two groups is high, then high-signaling whites are desirable partners but high signaling blacks are hard to distinguish from low-signaling blacks-- it becomes optimal to trade exclusively with highsignaling whites.

In Figure 3, we vary the relative size of the signaling (white) group. As $\mu$ rises, the cost of excluding the minority group in its entirety falls, and the discriminatory exclusive strategy eventually yields the highest return to the searcher. In general, the selective and exclusive strategies become more attractive as the relative gain to trading with a high-ability partner rises, as the accuracy of the signal increases, and as the relative size of the group about whom the searcher is informed rises. As the informational distance between groups increases, the strategy of being selective with regard to both whites and blacks becomes less attractive and is replaced with a racially-specific strategy, either selective with respect to whites only or exclusive.

\footnotetext{
${ }^{15}$ For $\omega=1 V\left(s_{H}, s_{L} ; I_{W}\right)$ is never optimal, but see Figure 2 for lower values of $\omega$.
} 


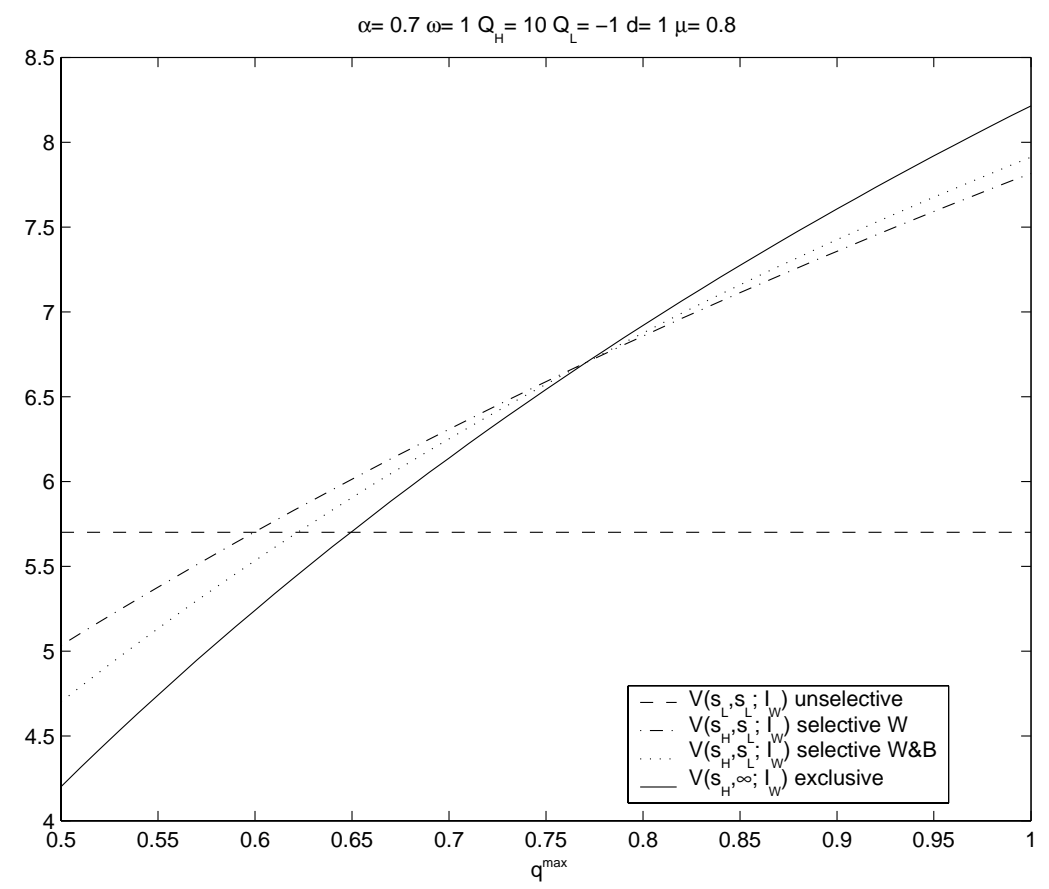

Figure 1

Value Functions for Alternative Strategies: Varying Signal Accuracy

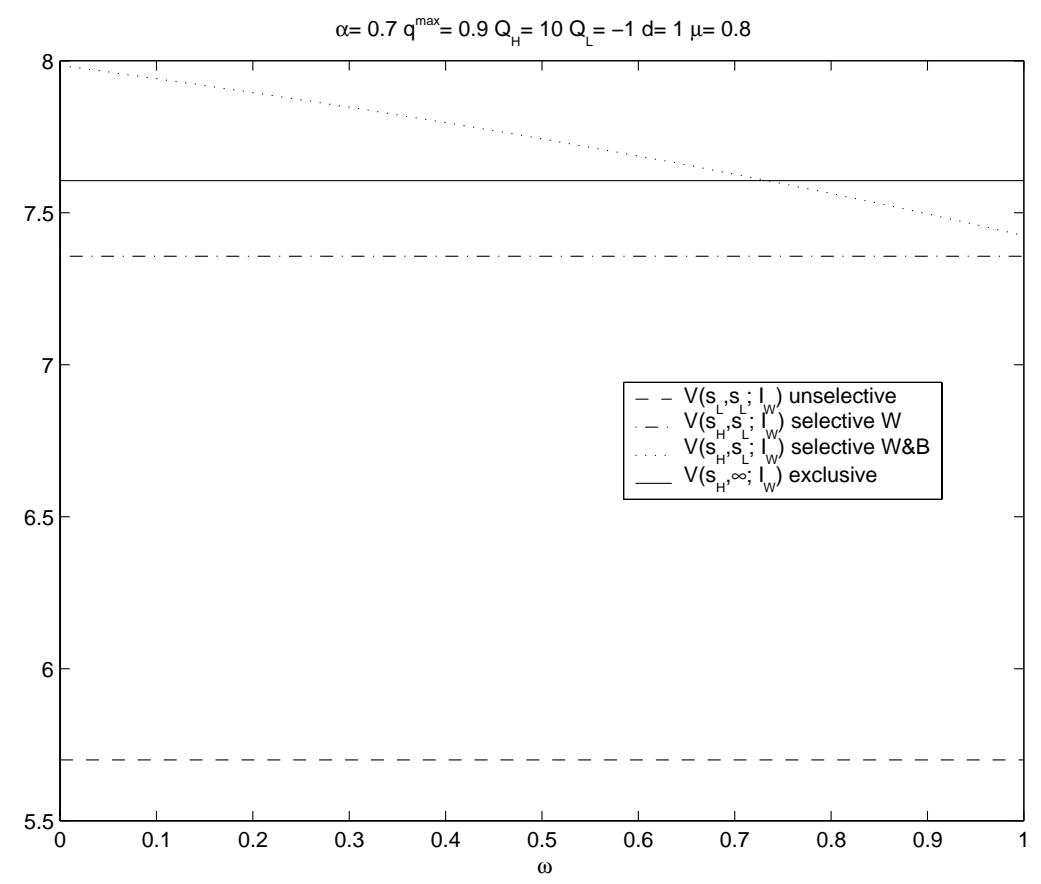

Figure 2

Value Functions for Alternative Strategies: Varying Informational Distance 


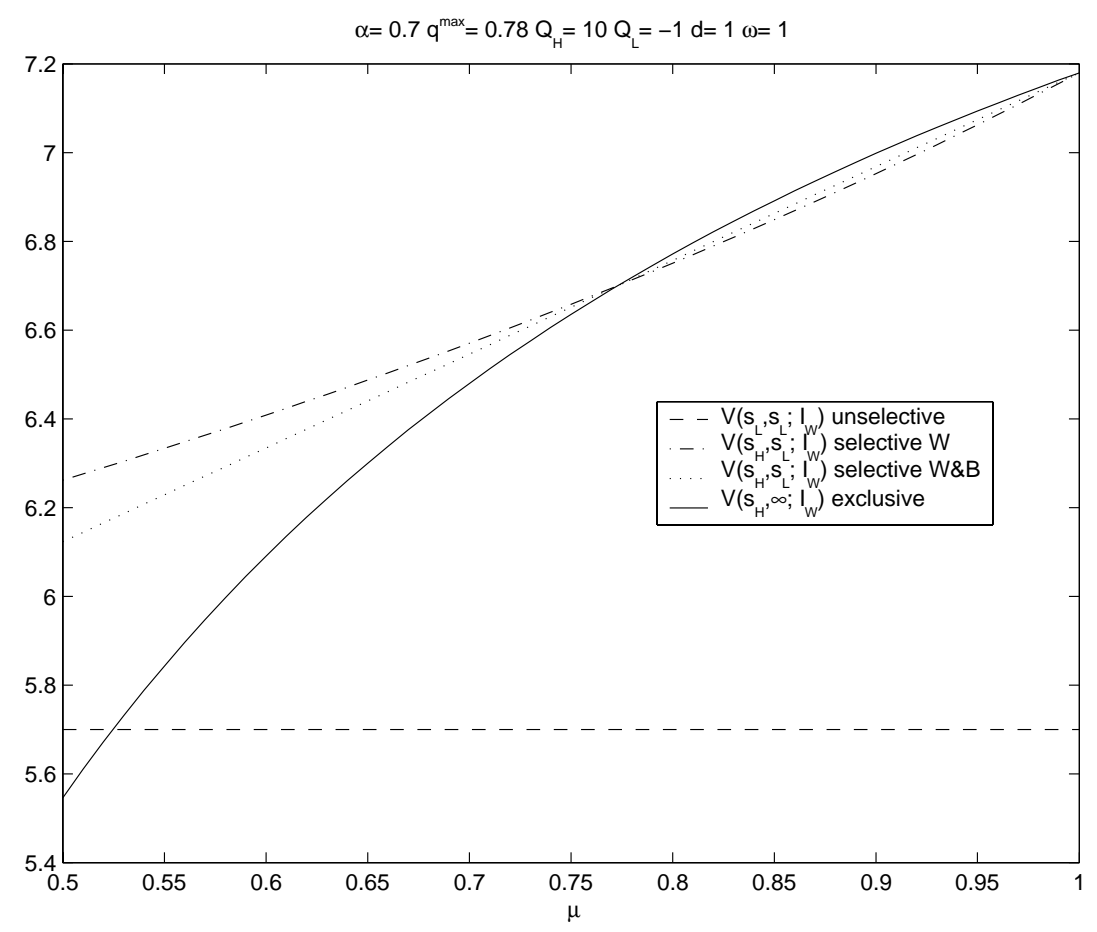

Figure 3

Value Functions for Alternative Strategies: Varying Group Size

Under what circumstances will agents exclude a group rather than trade selectively-in this case, by refusing to trade with any black partners? Returning to the value functions in (3), we can see that the relevant condition is $V\left(s_{H}, \infty\right)>R^{\omega}\left(s_{H}\right)$, or equivalently $V\left(s_{H}, \infty\right)>V\left(s_{H}, s_{H}\right)$. This gives us the racial exclusion restriction:

$$
\begin{gathered}
\frac{-d+\mu \cdot p\left(s_{H}\right) \cdot R\left(s_{H}\right)}{\mu \cdot p\left(s_{H}\right)}>R^{\omega}\left(s_{H}\right) \\
\mu \cdot p\left(s_{H}\right)\left[R\left(s_{H}\right)-R^{\omega}\left(s_{H}\right)\right]>d
\end{gathered}
$$

Examination of (4) provides three general results about conditions leading to discrimination in the form of exclusion of black partners from trade. 
- Racial exclusion is more likely when the minority is relatively small (large $\mu$ ).

As the black minority becomes smaller, ceteris paribus, the cost of foregone trade with this group becomes relatively unimportant and discrimination becomes more likely.

- Racial exclusion is more likely when the minority is informationally distant from the agent

An increase in informational distance, $\omega$, decreases $q^{i}$ and therefore $R^{\omega}\left(s_{H}\right)$, increasing the left-hand side of (4b). If agents have relatively little capability to distinguish the value of trade with high-signaling versus low-signaling black partners, then even high-signaling black partners have little appeal - as compared to high-signaling white partners - and all black partners can be excluded from trade at relatively low cost.

- Racial exclusion is more likely when the potential return from trade is high relative to the cost of search.

High search costs, relative to the potential return to trade, increase the cost of excluding potential partners.

In summary, we find that in a model of one-sided search with exogenous information, agents may choose to entirely exclude members of a minority group from trade for informational reasons, even though the distribution of characteristics in the minority group is known to be identical to the distribution of characteristics among the majority. Ceteris paribus, minorities are more likely to suffer such exclusionary treatment when the minority is small relative to the overall population and when the minority is informationally distant from the majority. 


\section{Model 2: Two-Sided Search with Differential Information}

An important element of Model 1 is that the searchers are homogeneous: they are undifferentiated by either race or ability. We turn here to a model of symmetric two-sided search in which both searchers and potential partners vary by race and ability, and a transaction occurs only if each party is acceptable to the other. A new strategic element is added by this dimension of the model — agents who are willing to trade with you need not be representative of all potential partners, or even of all potential partners who emit the same signal. The segregation that can arise in this model includes not only the exclusion of minorities found in Model 1, but also deliberate self-segregation by minority agents. In this model, high-ability black agents may choose to self-segregate because of the adverse selection problem generated by the discriminatory trading of white agents.

In the two-sided search model, heterogeneous agents search for transaction partners who are themselves heterogeneous. The agent observes the race of a potential trading partner, as well as an imperfect signal of the potential partner's ability. When two agents meet, each decides whether to offer to trade. If both agents, making simultaneous moves, offer to trade, a trade is executed, payoffs are received, and the period of the game ends. Conditional on a trade being executed, the payoffs to each agent depends on the abilities of both trading partners, $Q\left(a_{1}, a_{2}\right)$, $a_{i} \in\left\{a_{L}, a_{H}\right\}$, where $Q\left(a_{1}, a_{H}\right)>Q\left(a_{1}, a_{L}\right)$. If either agent declines to trade, both agents continue to search. ${ }^{16}$

We retain the assumption that the information structure is given exogenously; indeed, we adopt a rather extreme example of asymmetric information-blacks are fully informed about 
both groups (effectively $\omega=0$ ) while the majority group is fully informed about whites but relatively uninformed about the minority $(\omega>0) .{ }^{17}$ Since black agents have a greater (informational) endowment than whites, one might expect this to work to their advantage in a search equilibrium. We show that this is true in one-sided search but that more information need not lead to greater returns in two-sided search.

\section{$\underline{\text { A Numerical Example: One-Sided Search }}$}

To see the role played by adverse selection, we examine the choices made by agents with different abilities and different information sets in one-sided search. Suppose that blacks make up 10 percent of the population $(\mu=0.90)$; that there is a very high payoff for high-ability agents trading with high-ability agents (as in the sample payoff matrix in Table 1), so that there is a strong incentive to find a good match.

\begin{tabular}{l|l|l} 
& $a_{L}$ & $a_{H}$ \\
\hline$a_{L}$ & 1 & 5 \\
\hline$a_{H}$ & 5 & 500 \\
\hline
\end{tabular}

Table 1: Payoffs to Row Player $Q\left(a_{1}, a_{2}\right)$

Suppose also that 80 percent of agents are high ability $(\alpha=0.80)$; that signals are usually truthful $\left(q^{\max }=0.95\right)$, and that informational distance is at its maximum $(\omega=1)$. Finally, let the cost of a period of search be $d=0.95$. Table 2 shows the desired trades of each race/ability

\footnotetext{
${ }^{16}$ We assume throughout that agents sample with replacement from the pool of potential partners.
} 
group of searchers (columns) if they assume that any acceptable agents will be willing to trade with them. The first four rows show the expected gain from trade with each kind of observable partner, absent the strategic elements of learning and two-sided trading. Note that with $\omega=1$, white agents treat all potential black partners identically regardless of whether they signal high or low.

\begin{tabular}{|c|c|c|c|c|}
\hline & \multicolumn{4}{|c|}{ Race and ability of searchers } \\
\hline & $W a_{L}$ & $W a_{H}$ & $B a_{L}$ & $B a_{H}$ \\
\hline$W s_{H}$ & $4.95 \Rightarrow \mathrm{T}$ & $493.6 \Rightarrow \mathrm{T}$ & $4.95 \Rightarrow \mathrm{T}$ & $493.6 \Rightarrow \mathrm{T}$ \\
\hline \multirow{2}{*}{$\begin{array}{l}B s_{H} \\
\text { or } \\
B s_{L}\end{array}$} & \multirow[t]{2}{*}{$4.2 \Rightarrow \mathrm{T}$} & \multirow[t]{2}{*}{401} & $4.95 \Rightarrow \mathrm{T}$ & $493.6 \Rightarrow \mathrm{T}$ \\
\hline & & & 1.70 & 91.1 \\
\hline$W s_{L}$ & 1.70 & 91.1 & 1.70 & 91.1 \\
\hline$V^{*}$ & 3.66 & 492.2 & 3.71 & 492.3 \\
\hline
\end{tabular}

Table 2: Expected Gains from Trade and Desired Transactions

$$
(\Rightarrow \mathrm{T})
$$

\footnotetext{
${ }^{17}$ We adopt this assumption as a reasonable characterization of conditions in the United States, but note as further justification that, absent complete segregation, minority agents have a greater incentive to invest in information about the majority group than vice versa.,
} 
The last row shows the value associated with the optimal one-sided search strategy. For example, a white high-ability agent ranks trading partners: $W s_{H}$, all $B$, and $W s_{L}$. Taking into account the cost of search and the probability of making a match, $V$ is maximized when the searching agent trades only with whites signaling high. Note in Table 2 that cases where the expected return exceeds the value of continued search, $V^{*}$, are marked $\Rightarrow \mathrm{T}$, indicating that agents would like to make such trades in one-sided search. Note also that in this model, apparent gains from trade are higher for blacks than for whites, reflecting the former's informational advantage. With these parameters, high-ability whites choose to trade exclusively with whites who signal high, lowability whites trade selectively with whites who signal high and unselectively with blacks. All blacks trade selectively with members of both races who signal high. Thus, we have chosen parameters such that some white agents rationally discriminate against black partners, but blacks do not discriminate against whites.

However, the pattern of returns in Table 2 leaves black agents facing an adverse selection problem when they meet a white trading partner. A black agent can infer - and in this simple model can infer with certainty - that any white potential partner willing to engage in trade is of low ability, because the payoff structure gives high-ability partners a very strong incentive to be selective. Clearly, the desired transactions pattern in Table 2 cannot represent an equilibrium in the two-sided search model. When agents compute potential gain, they must account for the probability that a partner will trade with them. What is the Nash equilibrium for two-sided search? 


\section{Equilibrium Two-sided Search Strategies}

Let $N$ be a set of trading strategies; that is, a candidate Nash equilibrium. Then agents in each race/ability group $i$ choose an optimal strategy $N_{i}$ by maximizing the value function:

$$
V\left(N_{i} ; N_{-i}\right)=-d+p(T ; N) \cdot E(Q \mid T ; N)+(1-p(T ; N)) \cdot V\left(N_{i} ; N_{-i}\right)
$$

given the strategies $N_{-i}$ chosen by other agents, where $T=1$ if a mutually-agreeable trade occurs. For each agent type defined by ability $a_{l}$ and race $g_{l}, N$ maps each potential partner type (with signal $s_{2}$ and race $g_{2}$ ) into trade/no trade decisions: $N_{a_{1}, g_{1}}:\{W, B\} \times\left\{s_{L}, s_{H}\right\} \rightarrow\{1,0\}$. We compute the value functions in equation (5), and present the details in an appendix.

A set of strategies $N$ is a Nash equilibrium if each type of agent (black/white, high/lowability) is making the best response to the trade/no trade decisions of all other agents. Since each of the four kinds of agents can choose from $2^{4}$ possible strategies, there are $\left(2^{4}\right)^{4}$ possible equilibria. Nash equilibria can be found by computing all the possibilities. ${ }^{18}$

In general there will be multiple Nash equilibria, not all of them interesting. For example, the set of strategies in which no one trades with anyone is a Nash equilibrium, albeit one with infinitely negative value functions. We assume a trembling hand refinement criterion: Consider Nash equilibria where some elements of $N$ are zero; that is, one where some potential partners choose not to trade with a particular kind of agent. Suppose instead the partners "tremble" and may, with infinitesimal probability, mistakenly offer to trade. We retain only those equilibria in which strategies remain optimal when faced with this variation. Stated alternatively, we consider

\footnotetext{
${ }^{18}$ Something on the order of a million evaluations of the value function is required, a number small enough not to be a serious impediment.
} 
only those Nash equilibria in which all agents' strategies would be unchanged if those elements of $N$ where the probability of trade is zero were replaced by a small, positive probability.

The Numerical Example Revisited, with Self-Segregation of Minority Agents:

Using the same parameters as in the one-sided search example in Table 2, we numerically calculate the value functions for each agent type and strategy. An example Nash equilibrium is reported in Table 3. ${ }^{19}$ There are several important differences between the desired trades of onesided search and the equilibrium strategies in two-sided search. In two-sided search, low-ability black and white agents are now unselective in their search strategies, whereas both preferred to be selective in Table 2. High-ability white agents still trade only with similar partners, but highability black agents now refuse to trade with white agents who signal high, though they were willing to do so in the one-sided model..$^{20}$

${ }^{19}$ The Nash equilibrium is not necessarily unique even given the refinement we use. Since our interest is in showing that self-segregation may occur, not that it must occur, the other equilibria aren't relevant for our purpose. Nevertheless, we note that with these parameters there is only one other Nash equilibrium, one in which high-ability whites refuse to trade with whites who signal high. Unlike the equilibrium in Table 4, this equilibrium just illustrates the occasional self-fulfilling prophecy aspect of Nash equilibria. While high-ability whites are better off in the equilibrium in Table 4, neither equilibrium Pareto dominates across all race/ability groups.

${ }^{20}$ Low ability agents do not choose to self-segregate in this model because, already excluded from trading with high ability agents, they have nothing to gain. 


\begin{tabular}{|c|c|c|c|c|}
\hline & \multicolumn{4}{|c|}{ Race and ability of searchers } \\
\hline & $W a_{L}$ & $W a_{H}$ & $B a_{L}$ & $B a_{H}$ \\
\hline$W s_{H}$ & $4.17 \Rightarrow \mathrm{T}$ & $493.24 \Rightarrow \mathrm{T}$ & $1.00 \Rightarrow \mathrm{T}$ & 5.00 \\
\hline$B S_{H}$ & $1.00 \Rightarrow \mathrm{T}$ & 5.00 & $4.17 \Rightarrow \mathrm{T}$ & $493.24 \Rightarrow \mathrm{T}$ \\
\hline$B S_{L}$ & & & $1.04 \Rightarrow \mathrm{T}$ & 87.5 \\
\hline$W s_{L}$ & $1.04 \Rightarrow \mathrm{T}$ & 87.5 & $1.00 \Rightarrow \mathrm{T}$ & 5.00 \\
\hline$V^{*}$ & -2.41 & 491.8 & -3.58 & 480.26 \\
\hline
\end{tabular}

Table 3: Expected Gains and Equilibrium Transactions $(\Rightarrow \mathrm{T})$ in TwoSided Search

Why have high-ability blacks chosen to self-segregate in Table 3, though they did not do so in Table 2? Because high-ability whites discriminate, an offer by a white agent to trade with a black partner reveals that the white agent is of low ability. As $Q\left(a_{H}, a_{H}\right)$ is large, it now pays for high-ability blacks to be fussy. Though they look the same, the "strategic decisions" of highability blacks and whites are quite different. High-ability whites are unwilling to trade with any black agents for informational reasons. In contrast, high-ability blacks would be willing to trade with high-ability whites, but self-segregate because they know high-ability whites won't trade with them. 
The strategic choices made in two-sided search affect the relative gains of the two races. In the one-sided search shown in Table 2, the value of optimal search for black agents, $V^{*}$, is higher than white $V^{*}$ for both ability groups, reflecting the superior informational endowment of black agents. Contrast this with Table 3, where white gains exceed black gains in both cases. This switch is due to high-ability white partners excluding all blacks from trade. High-ability agents of both races refuse to trade with agents signaling low, but the exclusionary strategy of high-ability whites eliminates possible trades for low-ability black agents when they randomly signal high. This costs low-ability blacks more than does the analogous loss to low-ability whites because it is more costly to be excluded by the majority group than the minority group.

What factors contribute to an equilibrium with mutual segregation? Given that we've solved for equilibrium through a numerical example, we cannot provide a general characterization of equilibrium strategies in this model. However, we can draw some general conclusions about the margins on which racial exclusion decisions are made. We need to ask first what leads high-ability whites to refuse trade with blacks, and second, when does the adverse selection of white partners dominate the advantages of trading with the majority group for high-ability blacks?

As in Model 1, high-ability whites refuse to trade with blacks if the value of information is high relative to the cost of search, the informational distance between blacks and whites is large, and if black agents are a small proportion of the population. Information is valuable to able agents when $Q\left(a_{H}, a_{H}\right)$ is large and as $q^{\max } \rightarrow 1$. Consider this extreme case from the point of view of able whites. If able whites trade only with whites signaling high, they will execute trades at a fraction $\mu \cdot \alpha$ of their meetings; all offers to trade will be accepted and will yield 
$Q\left(a_{H}, a_{H}\right)$. So the value of their program will be $V^{*}=-d+\mu \cdot \alpha \cdot Q\left(a_{H}, a_{H}\right)+(1-\mu \cdot \alpha) V^{*}$, or $V^{*}=Q\left(a_{H}, a_{H}\right)-d /(\mu \cdot \alpha)$. Accepting a trade with a black agent has value $Q\left(a_{H}, a_{H}\right)-(1-\alpha) \cdot\left(Q\left(a_{H}, a_{H}\right)-Q\left(a_{H}, a_{L}\right)\right)$. So high-ability whites will exclude blacks if the former is greater than the latter, $\mu \cdot \alpha \cdot(1-\alpha) \cdot\left(Q\left(a_{H}, a_{H}\right)-Q\left(a_{H}, a_{L}\right)\right)>d$. Continuing the example, if high-ability blacks self-segregate they will execute trades with like agents receiving $V^{*}=Q\left(a_{H}, a_{H}\right)-d /((1-\mu) \cdot \alpha)$. The opportunity to trade with a white agent is worth $Q\left(a_{H}, a_{L}\right)$, so black agent will self-segregate if $(1-\mu) \cdot \alpha \cdot\left(Q\left(a_{H}, a_{H}\right)-Q\left(a_{H}, a_{L}\right)\right)>d$. "Voluntary" self-segregation requires first that whites choose an exclusive trading strategy so that black agents face an adverse selection problem. Given this adverse selection,

- Black agents are more likely to self-segregate when the minority group is relatively large, conditional on not being so large as to eliminate exclusive trading among whites.

The larger pool of minority partners reduces the opportunity cost of foregoing trade with low ability whites.

- Black agents are more likely to self-segregate when the minority group is informationally distant from the majority.

Voluntary self-segregation requires that in a one-sided trade equilibrium whites choose exclusive trading while blacks choose selective trading. This is more likely to happen when the minority group is informationally distant from the majority because, given the assumed informational asymmetry, blacks are better able to distinguish white ability than vice versa. 
The final result in this section is

- Minority welfare may be lower than majority welfare despite the minority's greater informational endowment and identical productivity distribution.

Tables 2 and 3 show an example of this outcome. Though minority workers are better informed than majority workers, their own signals may be of low value in equilibrium. If high ability members of both groups refuse cross-group trades, it is not surprising that the minority group suffers more, since it relinquishes more trading opportunities than does the majority group.

\section{Model 3: Search with Learning}

In previous sections, as in models of statistical discrimination, informational "distance" between races is assumed. This assumption can be motivated by appealing to premarket exposure to one group through family or segregated neighborhoods, but in this section we examine more formally how such racial differences in information might arise endogenously in a search model with learning. Completed transactions enable the searcher to learn about the relationship between the signal and the quality of potential partners, so that the quality of information (i.e. informational distance) about a group is endogenous with respect to transactions choices. We construct a two-period model in which, if learning in the first period is groupspecific, then searchers may treat the two groups differently in both periods, and may even refuse to transact with one group altogether.

As above, let group membership in this model be an easily-observable characteristic that is unrelated to the true quality of the potential partner. We make only the minimal informational assumption required to generate differential treatment: that searchers tend to conduct inference 
on the signal-quality relationship separately for the two groups - i.e. they believe that the two groups are "different." ${ }^{21}$ Search takes place in two periods. In the first period, the searcher is completely uninformed $\left(q=\frac{1}{2}\right)$ about partner signal-quality relationship, although population parameters are common knowledge. We assume a very simple learning process: as a result of a completed transaction in the first period, the searcher becomes fully informed $\left(q=q^{\max }\right)$ about the group they have experienced, while the information about the other group depends on the distance between the groups $\left(q=(1-\omega) q^{\max }+\omega \cdot \frac{1}{2}\right)$. The distance parameter now captures the extent to which the searcher is willing to generalize information acquired about one group to the other group. We consider two variants: one in which first-period search is myopic, so that the searcher conducts a transaction with the first potential partner that they meet, and, alternatively, a perfect foresight model in which the value of information acquired in the first period is part of the return to a transaction.

Let us begin with second period search, and assume that in period 1, the searcher met with a $W$ partner and is now fully informed about the signal-quality relationship for group $W$. For group $B$ partners, the signal is uninformative. The searcher's problem is now analogous to that described in Model 1. The value of searching in period 2, given information about group $W$ signals, is:

$$
V\left(I_{W}\right)=-d+\mu V_{W}\left(I_{W}\right)+(1-\mu) V_{B}\left(I_{W}\right)
$$

where $V_{g_{1}}\left(I_{g_{2}}\right)$ is the value of meeting a potential partner from group $g_{1}$ when informed about group $g_{2}$. These value functions will depend upon the searcher's optimal strategy, which will

${ }^{21}$ The economic significance of individual membership in socially-defined "groups" is examined in 
consist of a pair of group-specific reservation signals. Information about one group will both increase signal quality for that group and increase the informational distance between the groups: we can see from Model 1 that this will make selective trading with the familiar group and exclusion of the other group more likely. The functions $V\left(I_{W}\right)$ and $V\left(I_{B}\right)$ are each increasing in the size of the known group, and $V\left(I_{W}\right)>V\left(I_{B}\right)$ whenever group $B$ constitutes a minority of the population.

The value of first period search is:

$$
V^{0}=-d+\mu D_{W}\left[R^{U}+V\left(I_{W}\right)\right]+(1-\mu) D_{B}\left[R^{U}+V\left(I_{B}\right)\right]+\left(\mu\left(1-D_{W}\right)+(1-\mu)\left(1-D_{B}\right)\right) V^{0}
$$

where $D_{i}=1$ if the searcher will engage in a transaction with a member of group $i$ and zero if the searcher refuses such transactions, and $R^{U}$ is the expected return to a first period transaction. The searcher maximizes this value function with respect to the first period strategy $\left(D_{W}, D_{B}\right)$, given that the second period strategy is optimal conditional on the information acquired in the first period transaction.

Consider first myopic search. Since the agent is completely uninformed in the first period all potential partners are equally attractive and the agent will trade at first opportunity. In the second period the agent's problem is the same as in model 1 , where the agent is informed about members of randomly met in the first period. Since agents will have become informed about members of each group in proportion to their representation in the population, we know that:

Durlauf [1997]. 
- Minority partners in the second period are more likely to be excluded from trade than are majority partners.

Now consider strategic search in the first period, in which the agent realizes that the first period trade affects the value of information available in the second period. In this case:

- It may be optimal for the searcher to refuse transactions with minority partners in period one, holding out for the more valuable information generated by a transaction with a majority partner.

This strategy is more likely if the cost of search is not too high, group $W$ is a sufficiently large majority of the potential partners, and a selective or exclusive strategy is optimal in period 2, e.g. when the informational distance is large. Thus when learning is endogenous, agents may refuse to deal with members of the minority group, even when uninformed about both groups, and even though the agents know that the two groups have identical distributions of all characteristics.

When learning about signals is important and is group-specific, minorities may be excluded from transactions by rational searchers who choose to deal only with the group about which they are informed. Even if first-period search is myopic, so that learning is random, more agents will have experienced transactions with, and therefore be informed about the majority group. If learning is strategic, the majority advantage is strengthened: agents may choose to learn about the majority group because information about them is more valuable. The informational distance between groups that plays an important role in Models 1 and 2 may be the result of, or be reinforced by, strategic learning as well as pre-market segregation of the groups. 


\section{Conclusions}

In this paper, we present search models of informational discrimination that generate racial disparities different from those in the statistical discrimination literature. With discrete transactions between heterogeneous and imperfectly-informed agents, equilibria can be characterized by racial segregation of transactions patterns and average discrepancies in the gains to trade experienced by black and white agents. This contrasts with the differences in marginal treatment in the compensation schedules for black and white workers in statistical discrimination models.

We show that minority agents are more likely to experience exclusion by searchers, even in the simplest model, and that exclusion of a group is more likely if signals are informative and agents are heterogeneous in transactions value. Learning exacerbates the disadvantages of being in a minority, since the returns to learning about a small group are relatively low. In a two-sided search model, segregation can arise not only because members of a minority group are excluded by uninformed agents, but also through self-segregation of the minority in response to the adverse selection that may result from discrimination.

These models can serve as illustrations of the minimal assumptions that are required for race to play a meaningful role in an economic model. A pervasive belief by agents that race defines meaningful groups, that blacks are "different" from whites, is sufficient to generate segregated transactions patterns and racial differentials in the gains from trade. If learning about signal-quality relationships is to some extent race-specific, then small initial differences in the quality of information (including those due solely to group size) can cause segregation and, potentially, a self-reinforcing cycle of ignorance and avoidance. 


\section{Appendix: Value of Search with Two-Sided Trade}

The expected return to a completed trade, conditional on the observed signal and given the races of the agent and partner and the agent's ability, is

$$
R_{a_{1}, g_{1}}\left(s_{2}, g_{2}\right)=Q\left(a_{1}, a_{H}\right) \cdot p_{a_{1}, g_{1}}\left(a_{H} \mid s_{2}, T\right)+Q\left(a_{1}, a_{L}\right) \cdot p_{a_{1}, g_{1}}\left(a_{L} \mid s_{2}, T\right)
$$

To compute the probability weights on the transactions returns in (6), we first note that by Bayes' Law:

$$
p_{a_{1}, g_{1}}\left(a_{H} \mid s_{2}, T\right)=\frac{p\left(a_{H}\right) \cdot \rho_{a_{1}, g_{1}}\left(s_{2}, T \mid a_{H}\right)}{p\left(a_{H}\right) \cdot \rho_{a_{1}, g_{1}}\left(s_{2}, T \mid a_{H}\right)+p\left(a_{L}\right) \cdot \rho_{a_{1}, g_{1}}\left(s_{2}, T \mid a_{L}\right)}
$$

The $\rho_{a_{1}, g_{1}}\left(s_{2}, T \mid a_{H}\right)$ term in the numerator of (7) is the probability that, given the potential partner is of high ability, they will have emitted signal $s_{2}$ and a trade will take place. This will depend on the partner's signaling probability conditional on ability, on the partner's equilibrium strategy and on the random signal emitted by the searcher.

$$
\rho_{a_{1}, g_{1}}\left(s_{2}, T \mid a_{H}\right)=\rho\left(s_{2} \mid a_{H}\right) \cdot\left[N_{a_{H}, g_{2}}\left(s_{L}, g_{1}\right) \cdot \rho\left(s_{L} \mid a_{1}\right)+N_{a_{H}, g_{2}}\left(s_{H}, g_{1}\right) \cdot \rho\left(s_{H} \mid a_{1}\right)\right]
$$

where $\rho(s \mid a)$ is the probability of meeting a partner who emits a signal $s$ given that the partner is of type $a$.

Equations (6) through (8) allow us to calculate $R($ ), the return conditional on completed trade. The probability that a trade is consummated, conditional on the observed characteristics of a potential partner, depends on the partner's true ability, the agent's random signal, and the partner's strategy, $N_{a_{2}, g_{2}}$. 


$$
\begin{aligned}
p_{a_{1}, g_{1}}\left(T \mid s_{2}, g_{2}\right) & =p\left(a_{H} \mid s_{2}\right) \cdot\left[N_{a_{H}, g_{2}}\left(s_{L}, g_{1}\right) \cdot \rho\left(s_{L} \mid a_{1}\right)+N_{a_{H}, g_{2}}\left(s_{H}, g_{1}\right) \cdot \rho\left(s_{H} \mid a_{1}\right)\right] \\
& +p\left(a_{L} \mid s_{2}\right) \cdot\left[N_{a_{L}, g_{2}}\left(s_{L}, g_{1}\right) \cdot \rho\left(s_{L} \mid a_{1}\right)+N_{a_{L}, g_{2}}\left(s_{H}, g_{1}\right) \cdot \rho\left(s_{H} \mid a_{1}\right)\right]
\end{aligned}
$$

For each type of searcher, the unconditional probability of trade is the sum of these conditional probabilities weighted by the probabilities of meeting partners with these characteristics, and by the agent's strategies.

$$
\begin{aligned}
& p_{a_{1} g_{1}}(T ; N)=\sum_{s_{2} \in\left[s_{L}, s_{H}\right]} \mu \cdot p\left(s_{2}\right) \cdot N_{a_{1} g_{1}}\left(s_{2}, W\right) \cdot p_{a_{1} g_{1}}\left(T \mid s_{2}, W\right)+ \\
& \sum_{s_{2} \in\left[s_{L}, s_{H}\right]}(1-\mu) \cdot p\left(s_{2}\right) \cdot N_{a_{1} g_{1}}\left(s_{2}, B\right) \cdot p_{a_{1} g_{1}}\left(T \mid s_{2}, B\right)
\end{aligned}
$$

Finally, the expected payoff from strategy $N$ weights the conditional returns $R($ ) by the probability of consummation and the population proportions.

$$
\begin{aligned}
& p_{a_{1}, g_{1}}(T ; N) \cdot E_{a_{1}, g_{1}}(Q \mid T ; N)=\sum_{s_{2} \in\left[s_{L}, s_{H}\right]} \mu \cdot p\left(s_{2}\right) \cdot N_{a_{1}, g_{1}}\left(s_{2}, W\right) \cdot p_{a_{1}, g_{1}}\left(T \mid s_{2}, W\right) \cdot R_{a_{1}, g_{1}}\left(s_{2}, W\right) \\
& +\sum_{l_{2} \in\left[s_{L}, s_{H}\right]}(1-\mu) \sum_{s_{2} \in\left[s_{L}, s_{H}\right]}(1-\mu) \cdot p\left(s_{2}\right) \cdot N_{a_{1}, g_{1}}\left(s_{2}, B\right) \cdot p_{a_{1}, g_{1}}\left(T \mid s_{2}, B\right) \cdot R_{a_{1}, g_{1}}\left(s_{2}, B\right)
\end{aligned}
$$




\section{References}

Aigner, Dennis J. and Glen G. Cain, "Statistical Theories of Discrimination in Labor Markets," Industrial and Labor Relations Review, January 1977, 30, 175-187.

Altonji, Joseph G. and Rebecca M. Blank, "Race and Gender in the Labor Market," in Orley Ashenfelter and David Card, eds. Handbook of Labor Economics, Volume 3C.

Amsterdam: Elsevier Science, 1999, 3143-3260.

Arrow, Kenneth, "The Theory of Discrimination," in Orley Ashenfelter and Albert Rees, eds. Discrimination in Labor Markets. Princeton, N.J.:Princeton University Press, 1973, 333.

, “What Has Economics to Say About Racial Discrimination?" Journal of Economic Perspectives, Spring 1998, 12(2), 91-100.

Bertrand, Marianne and Sendhil Mullainathan, "Are Emily and Greg More Employable than Lakisha and Jamal? A Field Experiment on Labor Market Discrimination," NBER Working Paper No. w9873, July 2003.

Coate, Stephen and Glenn Loury, "Will Affirmative Action Policies Eliminate Negative Stereotypes?” American Economic Review, December 1998, 83(5), 1220-1242.

Cornell, Bradford, and Ivo Welch, "Culture, Information, and Screening Discrimination," Journal of Political Economy, June 1996, 104, 542-571.

Durlauf, Stephen, “The Memberships Theory of Inequality: Ideas and Implications," in Elites, Minorities, and Economic Growth, E. Brezis and E. Temin, eds., North-Holland, 1999.

Durlauf, Stephen and H. Peyton Young. Social Dynamics. MIT Press, 2001.

Farley, Reynolds and William H. Frey, "Changes in the Segregation of Whites from Blacks During the 1980s: Small Steps toward a More Racially Integrated Society," American Sociological Review, 1994, 59, 23-45.

Glaeser, Edward L. and Jacob L. Vigdor, "Racial Segregation in the 2000 Census: Promising News," The Brookings Institution, Center on Urban and Metropolitan Policy, Survey Series, http://www.brook.edu/dybdocroot/es/urban/census/glaeser.pdf.

Holzer, Harry. What Employers Want: Job Prospects for Less-Educated Workers." New York: Russell Sage Foundation, 1996.

Lazear, Edward P., “Culture and Language,” NBER Working Paper 5249, Cambridge, MA: National Bureau of Economic Research, 1995.

Loury, Glenn C., "Discrimination in the Post-Civil Rights Era: Beyond Market Interactions," Journal of Economic Perspectives, Spring 1998, 12(2), 117-126.

Lundberg, Shelly J. and Richard Startz, "Private Discrimination and Social Intervention in Competitive Labor Markets," American Economic Review, June 1983, 73, 340-347. 
Mailath, George J., Larry Samuelson and Avner Shaked, "Endogenous Inequality in Integrated Labor Markets with Two-Sided Search," American Economic Review, March 2000, 90(1), 46-72.

Massey, Douglas, "The Age of Extremes: Concentrated Affluence and Poverty in the TwentyFirst Century," Demography, November 1996, 33(4), 395-412.

Massey, Douglas and Nancy Denton, American Apartheid: Segregation and the Making of the Underclass. Cambridge, MA: Harvard University Press, 1993.

O'Connor Alice, Chris Tilly, and Lawrence Bobo, eds. Urban Inequality: Evidence from Four Cities. New York: Russell Sage Foundation, 2000.

Phelps, Edmund S., "The Statistical Theory of Racism and Sexism," American Economic Review, September 1972, 62, 659-661.

Reardon, Sean F., John T. Yun, and Tamela McNulty Eitle, "The Changing Structure of School Segregation: Measurement and Evidence of Multiracial Metropolitan-Area School Segregation, 1989-1995," Demography, August 2000, 37(3), 351-364.

Spence, Michael, “Job Market Signaling,” Quarterly Journal of Economics, 1973, 87, 355-374.

U.S. Census Bureau, Current Population Reports P60-213, "Money Income in the United States: 2000,” U.S. Government Printing Office, Washington D.C., 2001. 